\title{
Orçamento participativo da educação: limites e possibilidades na experiência de União da Vitória/PR
}

\section{Participative financing plan of education: limits and possibilities of the experience of União da Vitória/PR}

\author{
Andréa Barbosa Gouveia*
}

\begin{abstract}
RESUMO
O presente artigo discute a questão da democratização do Estado a partir da análise da experiência da cidade de União da Vitória/ PR no desenvolvimento do Orçamento Participativo (OP) e, especialmente, do Orçamento Participativo da educação. Este desdobramento temático no campo da educação, confere uma peculiaridade a esta experiência e provoca o debate, tanto em relação à efetividade do controle popular sobre o Estado, quanto em relação à possibilidade do OP instituir uma discussão mais substantiva da política pública. Ao longo do texto procura-se cotejar os limites e as possibilidades deste processo.

Palavras-chave: democracia, política educacional, financiamento da educação.
\end{abstract}

\section{ABSTRACT}

The present article discusses the subject of democratization of the State with the analysis of the development of Participative Financing Plan of

* Professora do Departamento de Planejamento e Administração Escolar, Setor de Educação da UFPR. Mestre em Educação pela USP<andreabg@ufpr.br> 
Education experience in the city of União da Vitória/PR. This thematic unfolding in the field of education can reveal the peculiarity of this experience and provokes the debate, as much as in relation to effectiveness of popular control on State, as in relation to the possibility of Participative Financing Plan possibility institute a more substantial discussion of public politics. Along the text it tries to compare the limits and possibilities of this process. Key-words: democracy, education politics, financing of education.

A democratização do Estado e o controle público nas definições sobre a ação estatal são aspirações antigas que ganham, ao final do século $\mathrm{XX}$, novas possibilidades no cenário brasileiro. Do ponto de vista dos marcos institucionais nascidos do processo de redemocratização do país, as determinações, previstas na Constituição Federal de 1988, acerca de diferentes espaços de participação política, são o ponto inicial para o aparecimento de conselhos de diferentes tipos, que articulam a sociedade civil e o Estado na discussão e na fiscalização de políticas públicas. Porém, para além desta prática conselhista, a década de 90 vê se consolidar um outro tipo de articulação entre sociedade civil e Estado, em diferentes municípios brasileiros. Especialmente, para discutir o orçamento público, institui-se em Porto Alegre, no final da década de 80, e se expande para outros municípios, um processo denominado Orçamento Participativo, ${ }^{1}$ que incorpora práticas de constituição de conselhos de definição de políticas, com uma forma nova de mobilização direta da população, para debater e definir investimentos nos seus locais de moradia.

No âmbito da educação, a questão do controle público sobre as definições de políticas para a área é, também, uma formulação histórica dos educadores que se expressa, por exemplo, no inciso IV, do artigo 206, da Constituição de 1988, que institui a gestão democrática do ensino público como princípio para a organização da educação nacional. A partir deste dispositivo, a discussão sobre a necessidade da democratização da escola via conselhos escolares, eleição de diretores e da democratização do sistema por meio de práticas participativas de planejamento e gestão alimentaram a década de 90.

O presente artigo analisa a experiência do município de União da Vitória/PR, na gestão 1997-2000, que incorpora estas duas discussões, a democratização da definição do orçamento público e a democratização da

1 Ao longo do texto usar-se-á apenas OP. 
gestão da educação, pois neste período a cidade institui o Orçamento Participativo e cria uma derivação peculiar deste processo, o Orçamento Participativo da Educação. O objetivo central do debate neste artigo é de apontar elementos que permitam avaliar os limites e possibilidades do processo de democratização da gestão, via participação popular no debate sobre o orçamento público.

\section{O orçamento participativo no Brasil: a repolitização da esfera pú- blica}

Compreender a experiência de participação popular da cidade de União da Vitória, exige que a situemos como derivada de uma forma particular de proposta de participação da população na definição sobre o orçamento, qual seja, aquelas experiências que são articuladas por partidos do campo democrático popular (PT, PSB, por exemplo). Certamente, tal definição mereceria uma intensa discussão sobre o seu significado. Entretanto, não é possível fazê-lA neste artigo, o que torna fundamental chamar a atenção para o fato de que, sob o nome Orçamento Participativo não se encontram apenas propostas do campo democrático popular. ${ }^{2}$

Para caracterizar o OP que deriva de propostas de partidos democrático populares, em especial do Partido dos Trabalhadores, propostas estas que tomam como referência inicial a experiência de Porto Alegre, serão tomados os seguintes elementos, como características básicas deste processo: quem inicia o processo de debate do orçamento público; qual é a forma de participação da população; sob que critérios os recursos são distribuídos; a capacidade da população avaliar o próprio processo e o resultado dos debates; qual é o grau de autonomia da população frente ao processo de debate.

O primeiro elemento a ser considerado, certamente, é que a maior parte das experiências em curso tem no executivo o ponto de decisão e de

2 Há prefeituras de partidos conservadores como PFL, PPB e partidos de centro como PMDB que desenvolvem práticas de consulta à população para construção do orçamento municipal. 
articulação do processo de debate sobre o orçamento. A idéia de que o OP é um instrumento importante de democratização do Estado tem sido tomado como um dos eixos das campanhas dos candidatos do PT, no que ficou conhecido como Modo Petista de Governar. Tal compromisso com a democratização do Estado, via democratização de, pelo menos, parte da discussão sobre o orçamento municipal, encontrava-se na proposta de governo em União da Vitória.

A única exceção, quanto a origem do processo está na cidade de Porto Alegre, onde o movimento popular tem um papel decisivo na proposta do OP. Avritzer, ao analisar a experiência de Porto Alegre, destaca o papel do governo municipal na viabilização do OP, entretanto, nunca como uma mera concessão de poder, pois, segundo o autor:

Sem a contribuição decisiva da administração do PT na implementação da proposta, ela não teria se tornado realidade, mas é igualmente correto afirmar que a ausência do tema orçamento da proposta do governo do PT para a prefeitura de Porto Alegre demonstra que a identificação do tema orçamento foi obra do movimento comunitário (AVRITZER, 2002, p. 30).

Avritzer refere-se ao primeiro governo do PT em Porto Alegre, no qual apesar da questão da participação popular já se manifestar como compromisso de gestão, ela ainda não tinha ênfase na questão do orçamento. Segundo o autor o "primeiro documento em que aparece a expressão Orçamento Participativo é um documento da UAMPA ${ }^{3}$ em 1986" (AVRITZER, 2002, p. 28), pois a discussão petista, que embasava a proposta de governo, nesse momento voltava-se para a organização de Conselhos Populares. É o mesmo autor que afirma quanto ao processo em Porto Alegre:

O PT não tinha originalmente uma proposta de orçamento participativo, mas apenas uma proposta genérica de governo participativo. (...) quatro passos em direção à constituição do orçamento participativo coincidiram 
no começo da administração Olívio Dutra: ${ }^{4}$ a preocupação do movimento comunitário com o controle do orçamento e sua definição em nível local; a ênfase dada pelo Partido dos Trabalhadores à participação em conselhos; e a iniciativa descentralizada de diversas secretarias, inclusive a secretaria de planejamento, de encorajar a participação popular e, pouco depois, a iniciativa de centralizar todas as formas de participação na Coordenação de Relações com a Comunidade. (AVRITZER, 2002 b, p. 574-575)

Cabe lembrar que tal debate se faz no final da década de 80, quando o que está em pauta no conjunto das reivindicações do movimento popular, do movimento sindical, dos partidos de esquerda que estão se reorganizando, é a democratização das relações entre Estado e sociedade. A própria fundação do PT se faz sob a égide destes temas e, portanto, a proposta do governo petista, eleito em Porto Alegre nesse período, tomará o controle público do Estado pela sociedade como questão central na sua estratégia de governo.

Destarte, quando Avritzer destaca a negociação entre o governo Olívio Dutra e o movimento popular em Porto Alegre, para definição da necessidade de discutir o orçamento municipal, o que está em questão é a via de mão dupla no processo de construção do OP nessa primeira experiência, uma vez que, é o movimento popular organizado que coloca o acento da participação naquilo que considera central na ação do Estado - o orçamento público -, mas também há um movimento do próprio poder público municipal em reorganizar a forma de fazer política pública para viabilizar a discussão com a população. Portanto, inspiradas nesta primeira ${ }^{5}$ e original forma de articulação entre Estado e sociedade, dezenas de cidades constroem OPs próprios, por iniciativa, predominantemente, do poder executivo.

A forma de participação da população neste processo, segundo elemento de caracterização do OP, supõe "regras claras, públicas e conhecidas como garantia de universalidade e confiabilidade do processo" (CARVALHO, 2000, p. 36). A idéia de universalidade, diz respeito à participação,

4 Olívio Dutra foi eleito prefeito de Porto Alegre nas eleições municipais de 1988.

5 Vários autores vão destacar experiências anteriores a de Porto Alegre como marcos da participação popular, especialmente Lages(RS) e Piracicaba (SP), entretanto entende-se que apesar de importantes, tais experiências são diferentes do processo instituído em Porto Alegre e este último tem influência determinante na década de 90 no Brasil. 
ou seja, as experiências de OP organizam-se a partir de regras de participação que possam contemplar o conjunto da população da cidade. Por isso, a população é chamada a discutir na sua região ou sobre um tema que tenha relação mais direta com seus interesses imediatos. Isto tem relação com o grau de organização da sociedade civil, dos movimentos populares e com a possibilidade de pensar a participação popular não só nesta discussão, mas no conjunto de espaços como conselhos e similares, nos quais se discutem políticas públicas.

No sentido de procurar instituir formas amplas de participação da população no debate acerca das definições orçamentárias, a utilização de uma divisão geográfica da cidade está presente em todas as cidades onde há OP. Tal divisão, pauta-se pela organização de reuniões ou plenárias em bairros ou regiões, a depender do tamanho da cidade. Um caso curioso é o de Icapuí - CE, onde a metodologia de discussão do OP prevê uma etapa anterior às Plenárias Comunitárias, momento este denominado mobilização. Esta, consiste na visita, pela equipe do OP, à comunidade, para movimentar a população para as reuniões e levantar previamente as prioridades do local. O resultado desta pesquisa inicial serve como parâmetro para discussão na plenária. Esta é uma das dinâmicas, entre muitas, que comprova aquilo que Avritzer afirma acerca da democracia deliberativa, ou seja, ela se constrói com diferentes possibilidades locais e atuação de diferentes sujeitos.

Ainda pensando nas formas construídas nas diferentes cidades para buscar a universalização da participação, destaca-se a incorporação de Plenárias Temáticas de diferentes formas em cada cidade. Neste sentido, são exemplos interessantes: Belém/PA, onde na gestão 97-00, foram realizadas três plenárias temáticas: 1) Saúde para Todos, 2) Dar um Futuro às Crianças e Adolescentes, 3) Infra-Estrutura Urbana e Desenvolvimento Econômico, além do chamado OP da juventude, que é, de certa forma, também temático. Belo Horizonte/MG, onde na gestão 97-00, além de plenárias temáticas realizava-se um OP-Habitação. União da Vitória/PR, gestão 9700, a plenária temática tomou uma forma muito específica de separação de uma parte dos recursos de investimento para discussão exclusiva com a comunidade escolar, o chamado OP-Educação.

Enfim, a forma que as temáticas vão se definindo em cada local depende das dificuldades, das necessidades e da organização de cada espaço e revelam a diversidade de soluções para ampliar as possibilidades de discussão das questões. 
Outra dimensão da discussão sobre as formas de participação da população, diz respeito ao quanto tal participação é direta ou representativa. Esta participação é direta no momento das plenárias, mas também é representativa nos Conselhos do OP, de forma que não é possível caracterizar este processo exclusivamente como construção de uma democracia direta, mas é preciso considerá-lo como um processo mais complexo no interior da democracia representativa. Ele articula espaços de democracia direta com novas formas de representação e ainda uma interseção com o aparato institucional da democracia representativa, uma vez que, para que o OP se torne ação, as prioridades da comunidade precisam compor a peça orçamentária a ser remetida ao Legislativo.

A participação direta tem sua realização no âmbito das plenárias gerais ou temáticas nas quais o critério para participação é de interesse no tema ou local de moradia. A nova instância representativa, criada pelo OP, são os Conselhos, estes têm a tarefa de montar o formato final da proposta orçamentária e, mais que isto, negociar e ajustar as prioridades entre as regiões. O Conselho discute a versão final da LDO e da LOA com base em critérios definidos, no âmbito do próprio Conselho, no início do processo. A composição dos Conselhos do OP é, predominantemente, resultado da eleição de delegados nas plenárias regionais e temáticas, mas incorpora também representantes de segmentos organizados da sociedade civil. É este o caso, por exemplo, de Belém/PA onde, além de delegados titulares e suplentes eleitos nas plenárias, o Conselho é formado por um titular e um suplente de cada Sindicato de Servidores Públicos Municipais e um titular e um suplente para cada entidade geral do movimento popular da cidade. Em todos os Conselhos também estão presentes representantes do Executivo, sob diferentes composições; em Medianeira/PR, por exemplo, existem três representantes para o Executivo num conselho de mais de 40 membros. Em Icapuí/CE dos 19 representantes no Conselho, nove devem ser do Executivo. Em Belo Horizonte/MG, o Conselho segue a regra da paridade entre representantes do poder público e da sociedade civil. Na maior parte dos Conselhos, os representantes do poder público não têm direito a voto.

Este último aspecto é crucial para avaliar o poder efetivo de deliberação da população. A correlação de forças no interior dos Conselhos define, de certa forma, o grau de controle que a comunidade pode exercer sobre o Poder Público. Mesmo com esta regra do Poder Executivo não votar no Conselho do OP, deve-se considerar que os representantes do governo são 
importantes interlocutores, uma vez que, detêm uma parcela considerável das informações sobre o município, sobre o processo do orçamento, sobre as dimensões técnicas das obras, enfim informações que mesmo se democratizadas ao longo do processo são altamente relevantes no processo de argumentação. Com isto, evidencia-se que quando se fala em um certo apoio técnico não se está desconsiderando que os representantes do governo são sujeitos ativos nas disputas políticas. Este caráter híbrido do Conselho do OP, e mesmo do conjunto de plenárias, onde estão Estado e sociedade, disputando posições e construindo novos consensos, é o cerne da inovação, posto que esta relação se constrói num espaço que não é estatal, mas é público. É da sociedade civil, mas não é parte do mercado. Neste sentido, podemos identificá-lo como esfera pública na acepção habermasiana ${ }^{6}$ e que tal espaço exige outra racionalidade nas decisões.

O terceiro elemento a ser considerado é o da existência de critérios para definição de demandas. Isto se relaciona à clareza nas regras, mas, também, assegura elementos para garantia de equidade de distribuição de recursos, de forma a que no OP se busque "compensar as carências na oferta de serviços e equipamentos públicos entre as diversas regiões" (CARVALHO, 2000, p. 39). Esta dimensão de uma certa objetividade dos critérios, de uma racionalização da distribuição dos recursos é reiteradamente destacada por autores que analisam a experiência de OP em Porto Alegre. Feddozzi é um destes autores que vê nas regras definidas previamente para distribuição de recursos, a grande possibilidade do OP:

Ao primar por regras universais e previsíveis de participação e por critérios objetivos e impessoais para a seleção das prioridades apontadas pelas comunidades, o OP estabelece uma dinâmica de acesso aos recursos públicos, que se opõe ao particularismo da "justiça casuística", isto é da prática de distribuição de favores sem atenção às normas universais necessárias à cidadania, como prática tradicional que caracteriza a gestão pública brasileira. (FEDOZZI, 2000, p. 68-69)

6 Para Habermas o espaço público é a "esfera cujo locus de organização é o espaço entre a sociedade civil e a autoridade estatal” (AVRITZER, 1996, p. 31). 
Esta definição da distribuição de recursos, ainda que diminua o casuísmo, incide em dois problemas: 1) a definição do montante de recursos a serem discutidos durante o processo do OP. Via de regra, as experiências registradas apontam para a discussão dos recursos de investimento, que são certamente a menor parte de qualquer orçamento. Isto não parece constituir um mal em si, mas é, evidentemente, um limite a ser ultrapassado posto que há nos recursos de manutenção uma ampla margem de manobra dos governantes. Se a proposta é de controle social sobre a ação do Estado, a parte maior do orçamento deve ser também passível de discussão, mesmo que isto mexa com rotinas já arraigadas na administração pública. 2) a própria definição de como os recursos destinados ao OP serão distribuídos entre as comunidades, e em que medida o próprio Executivo ou o Legislativo terão autonomia frente ao $\mathrm{OP}$, para identificar investimentos específicos.

As formas de enfrentamento deste último problema são muitas, a questão de critérios universais assegura unidade às experiências, a partir de uma diversidade considerável de formas de execução dessa discussão. Em Belo Horizonte/MG, por exemplo, os critérios incorporam a noção de qualidade de vida com a utilização de um "Índice de Qualidade de Vida Provisório,"7 aplicado anualmente, que define a proporção de recursos disponíveis para cada região. Em diferentes municípios como Chapecó/SC, Porto Alegre/ RS, União da Vitória/PR e outros, os critérios incorporam a composição de prioridade dada pelas pessoas presentes nas plenárias a cada demanda, tamanho da população de cada região da cidade, carência dos serviços ou obras em discussão, para por meio de um sistema de pesos e notas chegar a um índice de distribuição de recursos. Todas as experiências constroem formas de tornar esta disputa por recursos escassos, um processo que se paute em regras transparentes de decisão, nas quais os critérios de divisão de recursos são uma parte do processo, combatendo o tradicional clientelismo e favoritismo tão impregnado na administração pública brasileira.

Um quarto elemento de caracterização das experiências é a capacidade que a população tem de monitorar e avaliar o próprio processo e o resultado dos debates. Tal monitoramento exige o acompanhamento pela comunidade da execução do orçamento no ano subseqüente à discussão no $\mathrm{OP}$, de forma que possa avaliar os resultados e a qualidade dos serviços

7 Avritzer informa que o índice de qualidade de vida é o resultado de uma equação que considera os seguintes elementos: população da região, renda média da região e um divisor constante. (AVRITZER, 2002) 
prestados ou obras executadas. Esta dimensão do acompanhamento e avaliação aparece, por exemplo, em União da Vitória/PR, onde cada obra passava por uma vistoria dos delegados do $\mathrm{OP}$ antes de ser entregue à população.

O quinto elemento fundamental na caracterização das experiências do OP diz respeito à existência de momentos em que a comunidade discute sem a presença do poder público, o que exige que o movimento popular se organize, mesmo que não em suas formas tradicionais, como associação de moradores e equivalentes, mas que as pessoas das comunidades se reúnam para preparar-se para as plenárias que indicarão efetivamente as prioridades. Um exemplo deste procedimento é do OP de Porto Alegre. Os relatos sobre o OP da capital gaúcha demonstram que o nível de detalhamento que a comunidade precisa chegar para indicar a obra a ser priorizada - os delegados devem entregar por escrito a obra definida na sua comunidade com o local preciso em que ela deve ser feita - exige um debate bastante explícito pela população envolvida em cada definição. Este momento autônomo das comunidades não está presente em todos os relatos de experiências e talvez seja uma diferença fundamental na discussão da relação entre o Executivo e o movimento popular. Em União da Vitória/PR tal prática não aconteceu ao longo dos quatro anos de implementação do OP.

Tal apresentação procurou evidenciar que o OP possibilita construir um espaço que não é parte do aparelho do Estado e que as diferentes experiências podem avançar, mais ou menos, em relação a democratização do controle do Estado, quanto mais o OP se constitua como um espaço da esfera pública, ou seja, entre o estatal e os espaços privados da sociedade civil. Evidentemente, é sempre preciso reforçar que tais elementos têm desenvolvimentos peculiares em cada localidade, ao mesmo tempo em que apresentam aspectos de desenvolvimento metodológico que lhes dão unidade.

\section{O OP em União da Vitória e os recursos para educação}

O Orçamento Participativo em União da Vitória, como de certa forma já se anunciou, foi fruto da ação do poder executivo municipal, posto que 
era um dos eixos da campanha do candidato do Partido dos Trabalhadores, eleito para a gestão 1997-2000. Na sua metodologia geral, estava presente a articulação entre instâncias de participação direta da comunidade (plenárias nas regiões) e instâncias representativas (reuniões de delegados e o conselho do OP), assim como a preocupação da definição de certa objetividade nos debates a partir da existência de diretrizes técnicas para investimento. Nesta questão, cabe destacar que estas diretrizes são fruto do debate dos delegados e dos Conselheiros do OP e não diretrizes existentes $a$ priori, não obstante as normas de segurança e afins terem sido considerados neste debate com a população. Para ilustrar tal procedimento, em 2000, por exemplo, algumas das diretrizes técnicas foram: "apoio à cultura, apoio à produção, áreas de lazer, centros comunitários, conserveiros, educação, estradas na zona rural, horas máquina, iluminação pública, pavimentação, reassentamento urbano, saúde, telefonia, tubulação." (UNIÃO DA VITÓRIA, 1999, p. 24). Para cada um destes temas definiram-se critérios de abrangência e o perfil das obras ou serviços passíveis de serem priorizados de forma a orientar a aplicação dos recursos. No caso da educação, as diretrizes afirmam que:

No grande tema educação contempla-se: Escolas de Ensino Fundamental (pré a $4^{\mathrm{a}}$ séries). Centros de Educação Infantil. Centro Universitário.As prioridades das comunidades que podem ser contempladas são:Compra de terrenos em unidades que possam centralizar maior demanda e que hoje haja necessidade real de expansão. Deve estar dentro do plano de expansão da SEMED ou Ação Social. Reforma de prédio (instalação elétrica, hidráulica, muro, coberturas, pintura, cancha de esportes, calçadas, etc). Ampliação (salas de aula, sala para biblioteca, áreas de estudo, sala da direção etc). Novas escolas - só serão construídas novas escolas onde houver demanda de alunos que não estejam sendo atendidos pelo sistema. (UNIÃO DA VITÓRIA, 1999, p. 25)

Além da definição de diretrizes técnicas, a metodologia do OP em União da Vitória previa a definição de critérios para distribuição de recursos. Tais critérios eram construídos de forma matemática, ou seja, baseados em um conjunto de elementos e pesos que ao se articularem permitis- 
sem hierarquizar as demandas e definir as obras a serem realizadas em cada região da cidade e o percentual de recursos a serem aplicados.

Do ponto de vista dos elementos propostos como caracterizadores do OP, o único que não está presente em União da Vitória é a previsão de momentos em que a comunidade discute sem a presença do poder público. O OP em União da Vitória dependia, no conjunto do processo, da intervenção e mobilização da equipe do OP, portanto, da ação afirmativa do poder público. Evidentemente, isto é um limite se o desafio for a efetividade do controle do Estado pela população, posto que, mudando o executivo a discussão pública do orçamento pode ser mais facilmente interrompida. ${ }^{8}$

Apesar de interessar caracterizar o OP em União da Vitória como mais uma experiência do conjunto da ação do campo democrático popular e, neste sentido, mostrar o que ela tem em comum com as outras. Interessa mais, do ponto de vista do debate sobre as possibilidades da ampliação da democracia deliberativa, ${ }^{9}$ analisar o que tal experiência tem de peculiar e, neste sentido, que contribuição a metodologia desenvolvida aí tem para disponibilizar ao debate geral.

União da Vitória, a partir do segundo ano da gestão, instituiu um elemento novo na metodologia do OP que atendia a uma demanda local. Há, em muitos OPs, a organização de plenárias temáticas, como já apresentamos no item anterior deste texto. Porém em União da Vitória mais que plenárias temáticas, a inovação foi a criação de um OP paralelo, o Orçamento Participativo da educação. Ele pode ser considerado paralelo, posto que o executivo reservou uma parte dos recursos para serem discutidos exclusivamente entre a comunidade escolar. ${ }^{10}$

O OP-Educação é fruto da I Conferência Municipal de Educação, que ocorreu em junho de 1998, com a presença de todos os profissionais da rede municipal de educação infantil e de ensino fundamental. Esta Conferência fez um balanço das necessidades do município e definiu eixos de

8 A fragilidade do processo de debate centrado na ação do Estado, comprova-se em União da Vitória, posto que tal processo é extinto em 2001 com a mudança de prefeito. O prefeito da gestão em análise não foi reeleito.

9 Toma-se aqui o termo democracia deliberativa, no sentido construído por Avritzer, como uma prática que busca avançar de forma substantiva na construção democrática a partir da possibilidade dos sujeitos atuarem na esfera pública numa perspectiva argumentativa. $\mathrm{Ou}$ seja, uma prática democrática que supere o simples reconhecimento da vontade da maioria por meio da instituição de espaços de debate público.

10 Em todos os outros casos estudados, as plenárias temáticas disputam com as plenárias por localização geográfica o mesmo montante de recursos. 
atuação da gestão. A questão do OP aparece, na Conferência, no momento de discussão das condições físicas e materiais das escolas. Ainda não como a idéia de um OP específico, manifestam-se, na plenária final da Conferência, posições contestando o espaço que a educação tinha no OP e na gestão como um todo. Dada a precariedade real de uma significativa parte dos equipamentos escolares, a reivindicação dos profissionais da educação era legítima e o encaminhamento dado pela gestão foi o de destinar um percentual dos recursos de investimento do OP-Geral, para uma discussão específica da educação. Importa salientar que estes recursos de investimento deveriam ser, ao longo da gestão, agregados ao montante da receita obrigatória para educação. ${ }^{11}$ Isto por uma razão prática, qual seja, os recursos constitucionalmente vinculados à manutenção e desenvolvimento do ensino eram insuficientes para a efetivação de um projeto de educação de qualidade.

O processo foi discutido no âmbito da Secretaria Municipal da Educação - Semed, com o apoio da equipe do OP-Geral e consistia em reuniões por escola e centro de educação infantil para a apresentação do OP, prestação de contas do exercício anterior (OP e outras questões do orçamento da prefeitura) e escolha de três prioridades para investimento dos recursos. Após a rodada de reuniões, realizava-se a Assembléia do OPEducação, na qual se definiam cinco prioridades municipais para educação, além da distribuição de recursos para as escolas. Assim como no OP-Geral, os critérios de distribuição dos recursos entre as escolas eram compostos de forma matemática:

Peso 5 - posição da prioridade na escola: prioridade 1, nota 5; prioridade 2, nota 4; prioridade 3 , nota 3. Peso 4 - carência do item na escola: de $0 \%$ a $20 \%$, nota 5 ; de $20 \%$ a $40 \%$, nota 4 ; de $41 \%$ a $60 \%$, nota 3 ; de $61 \%$ a $80 \%$, nota 2 ; de $81 \%$ a $100 \%$, nota 5 . Peso 3 - ênfase na qualidade: material pedagógico, 5; material esportivo, 4; espaço físico, nota 3. Peso 2 - população de alunos na escola: 400 a 500, nota 5; 300 a 400, nota 4; 200 a 300, nota 3,100 a 200, nota 2 ; menos de 100 , nota 1 . (UNIÃO DA VITÓRIA, 1998)

11 A destinação obrigatória segundo a Constituição Federal é de $25 \%$ da receita de impostos, mais $100 \%$ dos recursos do Fundef, mais 100\% dos recursos de convênios específicos. 
Tanto no OP-Geral quanto no OP-Educação, havia um acompanhamento do processo de votação do orçamento público na Câmara Municipal, assim como o decorrente acompanhamento da execução do orçamento, do andamento das obras e da qualidade do resultado.

Para compreender os limites e possibilidades desta metodologia, é necessário que se observe como os recursos foram distribuídos após o debate com a população. A tabela 1 apresenta a distribuição final dos recursos discutidos no âmbito do OP-geral, nos 4 anos da gestão. Observe-se que do primeiro para o segundo ano, os recursos destinados à educação diminuem e nos dois últimos anos crescem vertiginosamente. Tal variação é decorrente das próprias regras instituídas no processo pois, quando o OP-Educação é criado em 1999, o OP-Geral define que educação não deverá entrar no debate, posto que, já há um outro espaço para isto. Entretanto, no ano seguinte, a comunidade escolar vem de forma mais articulada participar do processo e recoloca no debate a necessidade de destinação de recursos para educação pois, no OP-Educação, os recursos deveriam ser destinados, prioritariamente, para material de consumo e parte da demanda das escolas era para reforma e construção. A distribuição de recursos no OP-Educação está na tabela 2.

TABELA 1 - DISTRIBUIÇÃO DOS RECURSOS DO OP-GERAL, UNIÃO DA VITÓRIA, 1997-2000, EM VALORES REAIS, IGPM DE MAIO DE 2002

\begin{tabular}{lrrrc}
\hline ORÇAMENTO PARTICIPATIVO & $1997 / 98$ & $1998 / 99$ & $1999 / 00$ & $2000 / 2001$ \\
\hline Pavimentação & $538.569,06$ & $383.061,19$ & $314.698,18$ & $233.696,23$ \\
Tubulação/esgoto & $447.930,21$ & $336.845,93$ & $196.995,56$ & $165.608,71$ \\
Subtotal & $986.499,27$ & $719.907,11$ & $511.693,73$ & $399.304,94$ \\
Iluminação pública & $160.554,34$ & $151.850,14$ & $108.933,98$ & $72.579,41$ \\
Áreas de lazer & $160.270,14$ & $25.974,55$ & - & - \\
Educação & $107.988,33$ & $91.435,70$ & $479.471,03$ & $539.273,60$ \\
Saúde & - & $379.827,47$ & $198.311,49$ & $303.084,03$ \\
Outros & 0,00 & $95.798,98$ & $151.297,20$ & $189.723,05$ \\
Total & $1.415 .312,08$ & $1.464 .793,95$ & $1.449 .707,45$ & $1.503 .965,00$ \\
\hline
\end{tabular}

FONTE: PREFEITURA MUNICIPAL DE UNIÃO DA VITÓRIA, 1997-2000. 
TABELA 2 - RECURSOS PARA EDUCAÇÃO, OP-GERAL E OP-EDUCAÇÃO, UNIÃO DA VITÓRIA, 1997-00, EM VALORES REAIS, IGPM DE MAIO DE 2002.

\begin{tabular}{lccrr}
\hline & $1997 / 98$ & $1998 / 99$ & $1999 / 00$ & $2000 / 01$ \\
\hline OP-Geral & $107.988,33$ & - & $398.779,19$ & $468.349,10$ \\
Ensino Fundamental & $15.552,88$ & - & $288.751,15$ & $346.159,27$ \\
Ampliação e reforma & $15.552,88$ & - & $288.751,15$ & $346.159,27$ \\
Educação Infantil & $92.435,45$ & - & $110.028,04$ & $122.189,83$ \\
Compra de Terreno & $35.168,95$ & - & - & - \\
Ampliação e reforma & $25.195,67$ & - & $110.028,04$ & $122.189,83$ \\
Equipamentos & $32.070,83$ & - & - & - \\
OP-Educação & - & $91.435,70$ & $80.691,84$ & $70.924,50$ \\
Ensino Fundamental & - & $74.967,68$ & $56.484,29$ & $49.647,15$ \\
Material pedagógico & - & $30.681,42$ & $10.031,61$ & - \\
Móveis e equipamentos & - & - & $17.448,00$ & $16.681,44$ \\
Material de informática & - & $26.322,64$ & $15.047,41$ & $17.525,44$ \\
Livros & - & $10.479,65$ & $7.851,32$ & $5.014,36$ \\
Recursos audiovisuais & - & - & $6.105,95$ & $9.035,78$ \\
Ampliação e reforma & - & $7.483,97$ & - & - \\
Investimento cultural & - & - & - & $1.390,12$ \\
Educação Infantil & - & $16.468,02$ & $24.207,55$ & $21.277,35$ \\
Material pedagógico & - & $5.042,21$ & $9.077,83$ & $2.829,89$ \\
Móveis e equipamentos & - & $1.946,22$ & $9.683,02$ & $13.128,12$ \\
Material de informática & - & - & - & $1.595,80$ \\
Livros & - & 646,74 & $2.219,83$ & - \\
Recursos audiovisuais & - & $5.539,24$ & $3.226,87$ & $2.829,89$ \\
Parquinho & - & $3.293,60$ & - & 893,65 \\
Total geral & $107.988,33$ & $91.435,70$ & $479.471,03$ & $539.273,60$ \\
\hline
\end{tabular}

FONTE: PREFEITURA MUNICIPAL DE UNIÃO DA VITÓRIA, 2000.

Tais indicações, sobre os resultados do debate sobre o orçamento em União da Vitória, permitem que avance um pouco na tarefa proposta inicialmente: quais são os limites e possibilidades deste processo?

Na discussão com a população, a instituição do debate e a atuação organizada da comunidade escolar, principalmente do envolvimento de diretores e de dirigentes sindicais, levaram a uma ampliação considerável dos recursos para a educação no âmbito dos recursos para investimento discutidos no OP.

Cabe ressaltar que o desenvolvimento peculiar do debate temático no OP de União da Vitória deixa uma contribuição do ponto de vista do desenvolvimento metodológico da participação popular no debate orçamentário, no sentido que, ao instituir um processo paralelo, apresentou-se nesse município uma possibilidade de tomar o debate da política pública de forma mais substantiva. Ou seja, a população que participou de plenárias nas creches e escolas de certa forma foi incentivada a pensar sobre os problemas 
educacionais do município. Entretanto, talvez tal aprofundamento se deu ao custo da perda do olhar sobre a totalidade das questões que afligem a cidade. Tal impasse foi pouco discutido pelos dirigentes do processo, que viam esta migração da comunidade escolar do OP-Educação para o OPgeral como uma aprendizagem:

Hoje, em termos de processo eu fico com o OP-Geral , o OP-Educação até serviu como isca. Valeu a pena porque eles foram para o orçamento geral. O OP-Educação chegou a esvaziar em uma altura, porque desmotivou. Tanto que no último ano, o número de participantes na escola, para a discussão do OP-Educação, tinha peso, era um dos critérios para motivar a participação. Só que nesta altura, esta mesma comunidade já havia entendido que o jeito dela buscar recurso era no OP-Geral, o OP-Educação era o "opzinho", que tinha pouco recurso. (Entrevista com a Secretária Municipal de Educação, gestão 97-00, 2001)

Por outro lado, é possível afirmar que os pais e a comunidade escolar em geral podem ter ido às plenárias do OP-Geral apenas para ajudar a escola e não para discutir a cidade. $\mathrm{O}$ aporte menor de recursos, com uma definição a priori do Executivo de que os recursos deveriam ir para compra de material didático, como forma de garantir investimentos na qualidade de ensino, não permitiu um processo no qual a comunidade tomasse esta decisão e por isto forçou a migração para o OP-Geral na busca de resolver os problemas visíveis e imediatos das escolas. Isto, de certa forma, pode ser compreendido por uma visão vanguardista das equipes, que o tempo todo sentem a pressão entre instituir a participação popular como princípio, mas não deixar que esta participação popular leve a decisões erradas.

Entretanto, é possível reconhecer que o espaço de debate no processo do OP-Geral foi ocupado, ao mesmo tempo em que existiam critérios objetivos de distribuição de recursos. Esta dimensão de repolitização do debate e de disputa de recursos é patente na experiência de União da Vitória e contribui para um novo desenho da ação do Estado na medida em que permite desfazer uma polarização, qual seja, a contraposição entre participação popular e a racionalidade técnica. Apesar de alguns dos trabalhos que analisam outras experiências do $\mathrm{OP}$, e dos próprios documentos das cida- 
des, fazerem uma referência insistente sobre o aspecto da existência de critérios para a distribuição de recursos, como sendo o que confere a confiabilidade ao processo do OP, parece que isto, sem a dimensão da recuperação da discussão política no espaço público, não teria sentido. O germe da democracia representativa está em grande parte no enriquecimento do debate pela ação que professores e diretores construíram ao defender a escola como prioridade da cidade em cada plenária.

A relação entre os dois processos, OP-Educação e OP-Geral, parece se fazer num movimento de contradição, que não conseguiu se resolver no período em que estes processos estavam em marcha. Se a positividade da iniciativa temática pode estar, exatamente, em não colocar o tema como mais um entre outros, neste sentido o OP-Educação, em União da Vitória, teria uma peculiaridade interessante a ser explorada. Ele é diferente da maioria das experiências do OP, na qual a diversificação das formas de organização das discussões na cidade - base geográfica combinada à base temática - não implica a segmentação dos recursos, mas a disputa pelas prioridades se faz no conjunto dos recursos de investimento. Em União da Vitória, a busca pela ampliação da participação dos sujeitos se fez na forma do OPEducação, que se constituiu como um processo concomitante ao OP-Geral. A contradição está no fato de que ao se constituir um OP paralelo, coloca-se em cheque o critério da construção de condições igualitárias, posto que perde-se na parte a discussão do todo.

Nas entrevistas, procurou-se provocar as diferentes pessoas a avaliar este processo e sua efetividade na discussão do conjunto da cidade, no sentido de pensar se a migração da comunidade escolar em busca de melhores condições para as escolas não poderia estar se sobrepondo àqueles problemas urgentes da cidade. A primeira provocação aos entrevistados foi o questionamento de que se houvesse um OP-Saúde, um OP-Habitação ou algo assim, não resultaria em curto prazo que este tema tivesse um crescimento tão significativo entre as prioridades gerais, quanto ocorreu com a educação. Os entrevistados parecem não concordar com este raciocínio, por um lado, por considerarem que a mobilização de professores e diretores de escola fizeram a diferença no processo. E, por outro lado, por considerarem que havia outras formas de discussão temática na cidade - Conselhos de Saúde, agentes esportivos nos bairros - e que mesmo assim o impacto foi diferente.

$\mathrm{Na}$ entrevista com o prefeito municipal, ele destaca várias tentativas de estabelecer o convencimento sobre a importância de cada uma das ações 
durante o debate nas diferentes plenárias com a comunidade. Este depoimento reforça a compreensão de que foi de fato pelo convencimento, decorrente da possibilidade da argumentação, que a educação e, em outro momento, a saúde ganharam um espaço importante no OP-Geral:

Na comunidade foi dez! Os professores, o pessoal participava, queria tubulação (...) Houve alguns atritos, algumas pessoas não conseguiram compreender muito bem que a educação ficou em primeiro lugar e a galeria que era importante ficou para traz (...) Um exemplo disso foi a saúde, que estava com dificuldade de passar como prioridade em 99, e eu fui a várias reuniões tentar sensibilizar a comunidade sobre a importância que era o programa da saúde da família... Quando é bem explicado, há uma formação na comunidade, a população abre mão do problema local. (entrevista realizada em agosto de 2001)

Por outro lado, uma das pessoas da equipe da Semed, destaca a relação de cumplicidade entre professores e pais de alunos no OP:

A saúde até ia às reuniões do OP-Geral, para defender a saúde. Mas aí quando a gente da educação defendia saúde e educação acabava passando. Se nós como professores conseguíamos defender educação, saúde e depois a rua, acabava passando assim. Porque quem ia às reuniões eram pais de alunos, então eles já têm uma relação com a gente. Isso já acontecia no OPEducação, os pais perguntavam para o diretor o que a escola estava precisando e votavam naquilo. E isto aconteceu também no OP geral (...) É claro que numa cidade pequena o professor acaba sendo referência no bairro em que mora. (entrevista com técnico da SEMED, gestão 97-00, realizada em agosto de 2001).

A última afirmação da entrevistada, referindo as relações marcantes entre pais e professores como um dos motivos para a eficácia da intervenção dos últimos nas plenárias do OP, remete a discussão à própria cultura política da cidade que se institui num universo relacional (DA MATTA, 1997). 
Reconhecer isto como um limite dessa experiência não significa invalidá-la mas, pelo contrário, permite reconhecer que é preciso, além do espaço propício para que o debate se estabeleça, procurar instrumentos que alimentem, durante o processo, o olhar dos sujeitos sobre a totalidade. Com isto, pode-se reconstruir o universo relacional em bases de igualdade de condições de vida para a população e de forma que seja possível limitar a possibilidade da reprodução de interesses corporativos, mesmo que não se possa acabar com as corporações, até porque, em determinados momentos são salutares, por exemplo, quando consideramos como legítima a defesa da escola pública.

Enfim, como um processo em construção, o Orçamento Participativo tem um número imenso de possibilidades a serem testadas e ampliadas onde quer que se desenvolva. No caso específico de União da Vitória, a interrupção do processo nos seus primeiros passos deixa uma última questão, a necessidade de que o controle social sobre o Estado não dependa da iniciativa exclusivamente dos governantes para se instituir, dado o caráter efêmero dos governos.

\section{REFERÊNCIAS}

AVRITZER, L. A moralidade da democracia. São Paulo: Perspectiva/Belo Horizonte: Ed. UFMG, 1996.

Teoria democrática e deliberação pública Lua Nova. Revista de Cultura e Política. São Paulo, n. 50, p. 25-46, 2000.

Modelos de deliberação democrática: uma análise do orçamento participativo no Brasil. In: SANTOS, B. S. (Org.). Democratizar a Democracia: Os caminhos da democracia participativa. Rio de Janeiro: Civilização Brasileira, 2002b.

CARVAlHO, M. do C. A. A.; FELGUEIRAS, D. Orçamento Participativo no ABC. São Paulo: Pólis, 2000.

COUTINHO, C. N. Contra a corrente: ensaios sobre democracia e socialismo. São Paulo: Cortez, 2000. 
DA MATTA, R. A Casa \& a Rua. Espaço, cidadania e morte no Brasil. 5. ed. Rio de janeiro: Rocco, 1997.

FEDOZZI, L. Orçamento participativo, reflexões sobre a experiência de Porto Alegre. 2. ed. Porto Alegre: Tomo Editorial/Rio de Janeiro: Observatório de Políticas Urbanas e Gestão Municipal, 1999.

GIACOMINI, J. A comunidade como instância executora do planejamento: o caso do orçamento participativo de Porto Alegre. Revista de Administração Pública, Rio de Janeiro, v. 28, n. 2, p. 47-59, abr./jun. 1994.

GOUVEIA, A B. Orçamento participativo, controle social e o poder público municipal: a experiência de União da Vitória-PR (1997-2000). São Paulo, 2002. Dissertação (Mestrado) - FEUSP.

HABERMAS, J. Mudança estrutural da esfera pública: investigações quanto a uma categoria da sociedade burguesa. Rio de Janeiro: Tempo Brasileiro, 1984.

. A crise de legitimação do Capitalismo tardio. Rio de Janeiro: Tempo Brasileiro, 1999.

INSTITUITO PARANAENSE DE DESENVOLVIMENTO ECONÔMICO E SOCIAL Cadernos de Estatísticas Municipais: União da Vitória. Curitiba, 1998. Mimeog.

PREFEITURA MUNICIAL DE UNIÃO DA VITÓRIA Balanço Anual, 1997 1999. [c/autor: restante?]

. Proposta Orçamentária 1998. set. 1997. Mimeog.

. Proposta Orçamentária 1999. set. 1998. Mimeog.

. Proposta Orçamentária 2000. set. 1999. Mimeog.

. Proposta Orçamentária 2001.set. 2000. Mimeog.

. Assembléia Geral dos Delegados do Orçamento Participativo. jun. 2000, Mimeog.

Mimeog.

. Relatório do Orçamento Participativo. 1997-2000. dez. 2000. 